\title{
The Enlightenment on Campus Emergency Management
}

\author{
Ziliang An ${ }^{1, *}$, Ning Wang ${ }^{2}$, Junxiao Wang ${ }^{2}$, Dingsong $\mathrm{Bai}^{2}$, Shaofeng $\mathrm{Liu}^{2}$ \\ ${ }^{1}$ School of Urban Operations Management, Shanghai Urban Construction Vocational College, 201415 Shanghai, \\ China \\ ${ }^{2}$ School of Railway Transportation, Shanghai Institute of Technology, 201418 Shanghai, China \\ *Email: anziliang@succ.edu.cn
}

\begin{abstract}
The campus is a place where social talents are highly gathered. If an emergency occurs improperly handled, it will directly affect social stability. With the hot topic in the field of safety accidents in campus, the public awareness of emergency management has increased remarkably. In response to the current fragmentation dilemma of campus in China, it is necessary to improve the emergency management mechanism. In the paper, four evaluation strategies are proposed on the basis of existing research for the construction of campus emergency management system in China. It is imperative to build risk assessment capabilities and a collaborative mechanism for campus emergency management, while the campus should focus on the grassroots organization of student management and improve the legal system.
\end{abstract}

Keywords: Campus Emergency Management, Chinese characteristic, Evaluation Strategies

\section{INTRODUCTION}

Emergencies have all kinds of risks, such as unpredictability, contingency and contagion. At the same time, the campus is a public place, which has the characteristics of large population flow, high density, and high social attention [1-2]. Once an accident occurs, it will bring greater challenges and higher requirements to the emergency management of campus. Therefore, the campus has established an emergency management major, and actively responds to the emergency management mechanism formulated by the government. Confronted with the requirement of the emergency response capability, campus should fully understand severe challenges, although they have achieved positive results [3-5].

In this paper, the shortcomings of campus emergency management are reviewed from kinds of literatures, accident reports, news, etc. In order to improve the emergency management system, four evaluation strategies are proposed to predict the accident risk, which is dealing with the probability analysis model in big data process.

\section{DEVELOPMENT IN CHINA}

After emergency management became a prominent school in 2003, it has experienced rapid development and has achieved many research results in the past ten years. In 2018, the Chinese government established an emergency management department [6-9]. Although the campus incorporates emergency management into the curriculum construction, the government has not established a mechanism for campus emergency management. If an emergency occurs improperly handled, it will not only seriously damage the safety of life and property, but also directly affect social stability.

China's emergency management started late, so it will be of great use to formulate an emergency management system based on China's national conditions. Under the important instructions of General Secretary Xi Jinping on emergency management, as of early 2020, more than 7.8 million emergency plans have been prepared. During 2019, more than 3 million emergency drills were carried out nationwide. On October 13-14, 2020, the Emergency Management Department held a national emergency plan system construction site meeting in Shanghai, which discussed the long-term, complex, and systematic emergency management system [10-12]. As of August 2021, there are more than 50 universities and scientific research 
institutes in China that carry out emergency management disciplines, as shown in Table 1. The government can provide strong support for campus emergency management in terms of funds and policies, which improves the emergency management system and emergency response mechanism, and responds to campus emergencies more efficiently.

Table 1. List of campuses included in emergency management

\begin{tabular}{|c|c|c|}
\hline Affiliated Department & Campus & Content \\
\hline \multirow{3}{*}{$\begin{array}{c}\text { Directly under the } \\
\text { Emergency Management } \\
\text { Department }\end{array}$} & China Fire and Rescue Institute & $\begin{array}{l}\text { Talent training for the national comprehensive } \\
\text { fire rescue team }\end{array}$ \\
\hline & $\begin{array}{c}\text { North China Institute of Science and } \\
\text { Technology }\end{array}$ & Prominent in the field of safety engineering \\
\hline & Institute of Disaster Prevention & $\begin{array}{l}\text { Mainly in the field of disaster prevention and } \\
\text { mitigation }\end{array}$ \\
\hline \multirow{4}{*}{$\begin{array}{c}\text { Jointly established with the } \\
\text { Emergency Management } \\
\text { Department }\end{array}$} & $\begin{array}{c}\text { China University of Mining and } \\
\text { Technology }\end{array}$ & $\begin{array}{c}\text { School of Emergency Management and Safety } \\
\text { Engineering }\end{array}$ \\
\hline & $\begin{array}{c}\text { Beijing University of Chemical } \\
\text { Technology }\end{array}$ & $\begin{array}{c}\text { Open safety and emergency management } \\
\text { courses }\end{array}$ \\
\hline & $\begin{array}{c}\text { Xian University of Science and } \\
\text { Technology }\end{array}$ & Safety Science and Engineering Discipline \\
\hline & Liaoning Technical University & $\begin{array}{l}\text { Co-built by the Liaoning Provincial Government } \\
\text { and the Ministry of Emergency Management }\end{array}$ \\
\hline
\end{tabular}

In the past ten years, the government has continuously strengthened campus safety and established a corresponding emergency rescue system. However, there are still many problems in emergency management. Therefore, the situation of campus emergency management is still severe.

\section{CHALLENGES AND OPPORTUNITIES}

Although emergency management work has a certain foundation, it has not yet been able to establish a complete emergency system. Related research is still in the exploratory stage. There are mainly the following challenges:

Firstly, teachers and students lack crisis awareness. When faced with emergencies, they have a poor sense of self-help and cannot resolve the crisis in time. Many campus management levels do not have a sense of risk, and focus on the aftermath, so they are in a passive position.

Secondly, the grassroots management cannot achieve the most direct emergency response measures. Most campuses attach importance to the construction of mechanisms at the campus and department level, but ignore student dormitories and groups, which is precisely the most direct and critical first step in dealing with emergencies.
Thirdly, there is a lack of laws and systems for emergency management of campus emergencies. Although a series of emergency management laws and regulations have been issued at the national level, they have not specifically targeted campus emergencies.

Fourthly, a complete emergency management system of campus has not been established. Responding to campus emergencies is not only the responsibility of the security department and the logistics department, and it is also the result of cooperation between school institutions and social forces.

\section{EVALUATION STRATEGY}

There are several ways to improve China's emergency management of campus:

Firstly, it is imperative to build crisis awareness and risk assessment capabilities. The campus can add emergency handling content to the curriculum, in order to cultivate the crisis awareness and risk assessment capabilities of teachers and students. At the same time, the school increases emergency drills and training, especially starting from public health incidents. Only when teachers and students are familiar with the process of emergencies can the campus improve the emergency response level and comprehensive handling capabilities.

Secondly, the campus should focus on the grassroots organization of student management. Student 
management is a systematic project that runs through campus education, which requires the cooperation of individual students. Therefore, through grassroots management methods such as dormitories and groups, the campus cultivates student leaders and dormitory management teams. The purpose is to ensure rapid response in response to emergencies.

Thirdly, it is necessary to improve the legal system of campus emergency management. In the construction of the campus emergency management system, the government should be in a guiding position and play a guiding role, while the campus should combine actual conditions and improve the corresponding rules and regulations. Campus emergency management urgently needs an institutionalized, legalized, and scientific emergency management system, which is the basis for perfecting the collaborative mechanism.

Fourthly, it is very important to establish a collaborative mechanism for campus emergency management, as shown in Figure 1. Medical institutions, law enforcement agencies and other organizations around the campus form a community to build a collaborative mechanism involving multiple parties. The campus should establish a joint drill mechanism with all partners and conduct regular emergency drills. The campus should establish a joint drill mechanism with all partners to conduct regular emergency drills, which can increase the tacit understanding between departments and improve joint emergency response capabilities.

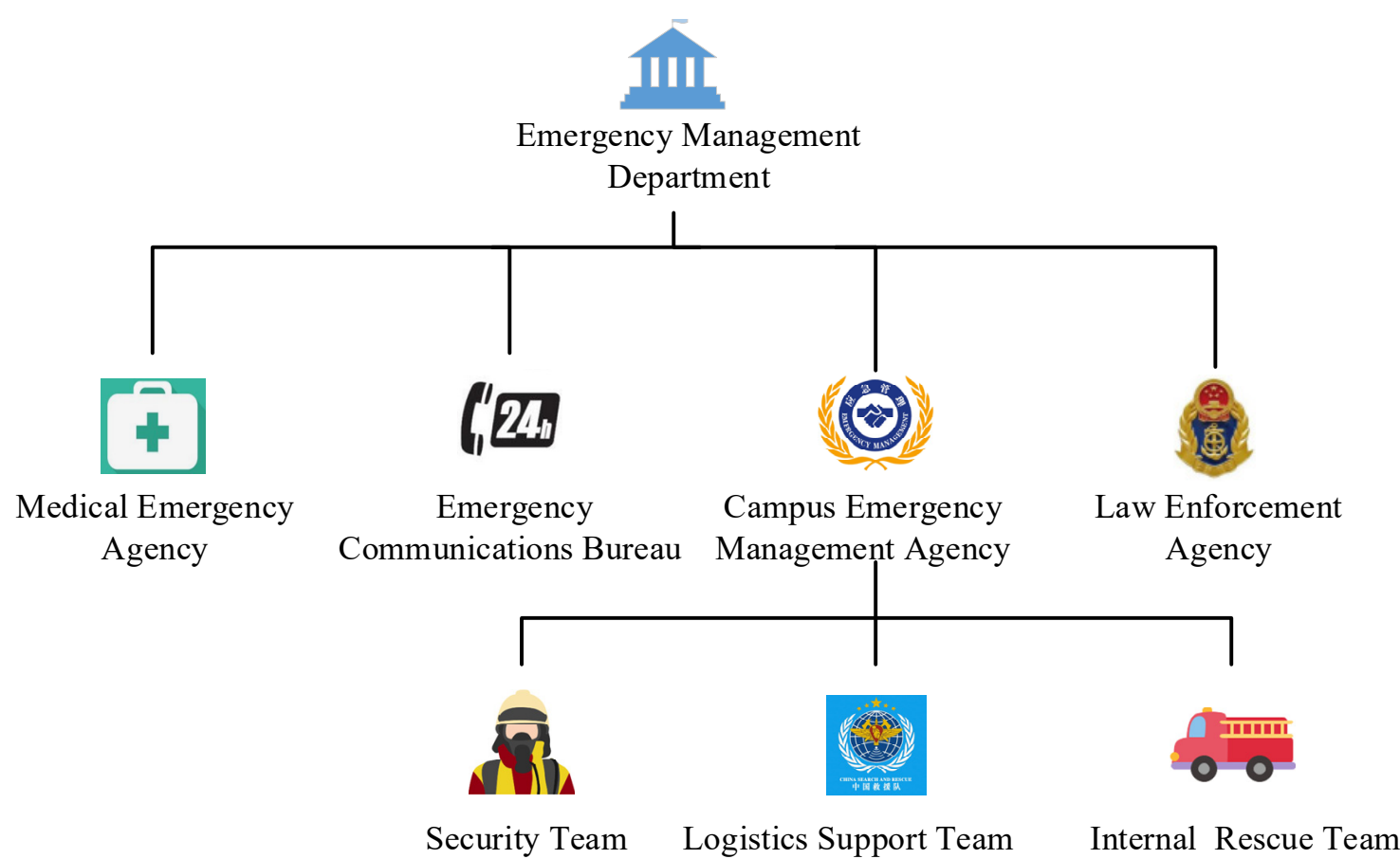

Figure 1 Collaborative mechanism for campus emergency management

\section{CONCLUSION}

Taking an overview of the campus emergency management, it presents a constantly improving situation, but the overall situation is still grim. Some campuses focus on education, but neglect campus emergency management. It can be seen that once a sudden safety accident occurs, the safety of life and property will definitely be endangered. Therefore, the campus should continuously improve emergency management with the government and all sectors of society in terms of overall planning, coordination and linkage, and system guarantees. Only in this way can we jointly promote the emergency management system and maximize campus safety.

\section{REFERENCES}

[1] Wang Li. Research on the Response and Handling Strategies of College Students' Emergencies. Chinese \& Foreign Corporate Culture, 2021(05): 114-115.

[2] Chen Wei, Zhou Fang, Fu Hongqing, Wang Mingzhu. Emergency response to campus emergencies and student management strategies. Electronic Technology, 2021, 50(06): 190-191.

[3] Chen Yinghua. An indomitable work, an outline of teaching practice-Comment on "Emergency Plan Preparation and Management". Safety \& Security, 2021, 42(08): 79-80. 
[4] Qian Xiaoping. Campus security management strategy based on collaborative governance. Electronic Technology, 2021,50(08):182-183.

[5] Lin Yongxing, Cao $\mathrm{Yu}, \mathrm{Wu}$ Yawen. The status quo, problems and countermeasures of emergency management education in Chinese universities. Beijing Education(Higher Education), 2021(08): 49-51.

[6] Qiao Fengfeng, Ding Zenghui, Lv Hongguo. Research on the planning and preparation elements of emergency plans for teaching activities in colleges and universities. Education and Teaching Forum, 2021(31): 45-48.

[7] Ruipeng Tong, Xu Xu, Wang Lulu, Guo Zimeng, An Yu. Exploration and prospects of emergency management talent training models in colleges and universities. China Safety Science Journal, 2021, 31(07):1-8.

[8] Ren Yuzhong, Lin Yongxing, Wu Xu. International Comparison and Enlightenment of Emergency Management Education. Journal of Party School Sichuan Provincial Committee of CPC, 2021(04):70-76.

[9] Gai Wenmei. The construction of my country's emergency management talent training system in the new era. Chinese Geological Education, 2021, 30(02): 29-32.

[10] Yuan Yuan, Liu Weirong. Strategies for emergency management of colleges and universities. Popular Standardization, 2021(12):212-214.

[11] Fang Jiating, Zhang Jinting. Research on University Emergency Management Mechanism in Major Public Health Emergencies. Invention and Innovation, 2021(06):82+112.

[12] Chen Pengyu, Suo Bomin. Thoughts on the training of government emergency management talents. Human resource development, 2021(08):10-11. 